\title{
ФАКТОРЫ ВЛИЯЮЩИЕ НА ФОРМИРОВАНИЕ ЦЕНЫ НА ПРОДУКЦИЮ АЛМАЗОДОБЫВАЮЩЕЙ ОТРАСЛИ
}

\author{
(c) 2019 Анисимова Алла Борисовна \\ кандидат экономических наук, доцент \\ кафедра экономики минерально-сырьевого комплекса \\ Российский государственный геологоразведочный университет им. Серго Орджоникидзе, \\ Россия, Москва \\ E-mail: ug26@list.ru
}

(C) 2019 Патрушева Елена Владимировна

кафедра экономики минерально-сырьевого комплекса

Российский государственный геологоразведочный университет им. Серго Орджоникидзе, Россия, Москва

E-mail: patrushevawork@yandex.ru

В статье рассмотрены основные факторы, влияющие на формирование цены на продукцию алмазодобывающей отрасли. Выявлена их взаимосвязь и общность, присущая выделенным алмазодобывающим странам/регионам. Помимо прямого влияния себестоимости добычи, обозначены факторы качества, регионального и природного значения, имеющие непосредственное отношение к колебаниям цены на готовое сырье.

Ключевые слова: алмазодобывающая отрасль, себестоимость добычи, качество сырья, мировой алмазный рынок, драгоценные камни, «кровавые алмазы», инвестиции.

Российская Федерация занимает первое место по запасам и объему производства алмазов в мире. На ее долю приходится треть общемирового производства алмазов, как в денежном выражении (29,11\%), так и в каратах $(28,24 \%)$.

Мировой рынок алмазного сырья представляет собой конкуренцию предприятий, занимающихся добычей и торговлей необработанными алмазами. Сегодня это девять стран и пять основных предприятий, совокупная доля общемирового производства алмазов которых, в натуральном выражении, составляет 99\%. Именно эти участники рынка формируют цену на алмазы и определяют вектор развития отрасли в целом.

Цена на продукцию представляет собой сумму стоимости всех затрат, понесенных в результате производства продукции, и так называемой прибавочной стоимости, или прибыли. Соответственно, определяя цену, которую можно выручить за производимый товар производитель должен помнить о трех ключевых факторах:

1. Себестоимость продукции, ниже которой цена, естественно не может быть установлена;

2. Цена продукции, установленная конкурентом, поскольку, установив свою цену ниже, предприниматель рискует упустить дополни- тельную часть прибыли, а если цена окажется более высокой - рискует вообще не реализовать продукцию;

3. Качество продукциии в сравнении с качество продукции у конкурентов.

В статье будет последовательно рассмотрено влияние всех трех факторов на ценообразование в алмазодобывающей промышленности.

\section{Себестоимость}

Алмаз - самый твердый минерал, что обуславливает его, в том числе неювелирные (технические) сферы применения. По шкале Мооса (параметров твёрдости) у графита начальная позиция, обозначенная 1, т.е. очень мягкий, а у алмаза - конечная, обозначенная 10 , т.е. самый твердый.

Алмаз является чистым углеродом, как и графит, их химическая формула С, а по твердости это противоположные минералы. Превращение самого мягкого камня в самый твердый на нашей планете происходит при очень высоких температурах (от $1100^{\circ} \mathrm{C}$ ) и громадном давлении (35 килобар и выше) глубоко под землей (от 100 километров) [4]. Именно в таких условиях происходит уплотнение кристаллической решетки и образуются алмазы, которые впоследствии перерастают в целые месторождения. 
В результате протекания природных процессов можно выделить следующие виды месторождений:

1. Коренные месторождения - образуются в результате выноса наверх потоками магмы при извержении вулканов.

2. Россыпные месторождения - в результате тысячелетнего разрушения трубок воздухом и дальнейшего их смыва осадками и ручьями. В результате чего создавались поля-россыпи, состоящие из щебня, гальки и алмазов.

3. Импактные - появились на местах падения метеоритов.

Виды месторождений обуславливают способы добычи алмазов: шахтный, карьерный или добыча из россыпей путем промывки. До XIX века алмазы добывались практически вручную - лопатой, разгребался речной песок и промывалась порода на лотках.

Независимо от способа добычи, реализация производства продукции алмазодобывающих предприятий (до непосредственной реализации) предусматривает следующие этапы формирования инвестиционных вложений:

- Геологоразведочные работы. Растянутый во времени (продолжительный цикл реализации каждой стадии) и высоконаучный процесс (представляет собой комплекс мероприятий, зачастую носящий уникальный, единичный характер). Этап локализации запасов, или обнаружения ресурсов, всегда сопровождается предварительными расчетами как для подтверждения масштабов объекта, его крупности, так и анализа экономической целесообразности его освоения.

- Оснащение работ соответствующими производственными мощностями (оборудованием). Современный этап развития алмазодобывающей отрасли фактически отказался от ручной добычи, выбирая более технологичную технику, которая нужна для обустройства шахты, транспорта для перемещения породы внутри технологического пространства.

- Вложения в развитие инфраструктуры (строительство подъездных путей, водо- и элетро- обеспечение производства и пр.) и региона в целом. На месторождении задействованы люди, для которых необходимо создать соответствующие условия жизни - питание, лечение, обучение, досуг. Поэтому часто рудник становится градообразующим предприятием. Сегодня рудник не просто «завод» по производству алмазов, но главный фактор развития региона.
Рудники инвестируют в программы, связанные с воздействием их производств на окружающую среду, стараясь минимизировать негативное влияние. Предприятия осуществляют финансирование местных систем здравоохранения (особенно актуально для африканского и азиатского континентов), внедряют и следят за соблюдением техники безопасности; вкладывают деньги в местные сообщества и учреждают стипендии, помогая молодежи учиться.

- Строительство обогатительной фабрики. Реализация сырья невыгодна и нерентабельна, поэтому сооружение обогатительного предприятия, на котором необработанные алмазы отделяют от породы, сортируют и отправляют на гранильное предприятие, также увеличивает инвестиционную нагрузку. На обогатительных предприятиях материал обработают, огранят и отшлифуют [1], тем самым осуществив первичное приращение цены готовой продукции.

Приведенные этапы включают в себя статьи, образующие сумму капитальных вложений, которая находится в прямой зависимости от типа месторождения и способа его добычи. Чем глубже залегает порода (для коренных месторождений), тем солиднее капиталовложения, связанные с доставкой руды на поверхность и ее последующим обогащением обогащением (или «облагораживаем»). Из россыпных месторождений добыча дешевле, чем из коренных. Для получения одного карата перерабатывают тонну шахтной породы (коренное), для россыпей показатель лучше - тонна породы даёт от трёх до пяти карат.

На горнодобывающих предприятиях капитальные вложения фактические составляют последующую себестоимость в долгосрочной перспективе, т.к. величина основных производственных фондов составляет более $80 \%$ от общего капитала.

Формирование себестоимости продукции на российских предприятиях алмазодобывающей отрасли осуществляется в рамках отраслевых инструкций:

- Инструкция по планированию, учету и калькулированию себестоимости продукции на предприятиях по добыче и обработке драгоценных металлов и алмазов (утв. Заместителем председателя Роскомдрагмета 28 февраля 1994 г);

- Инструкция по планированию, учету и калькулированию себестоимости продукции на 
предприятиях по изготовлению бриллиантов из природных алмазов (утв. Приказом Комитета РФ по драгоценным металлам и драгоценным камням от 10 сентября 1996 г. № 131);

- Инструкция по планированию, учету и калькулированию себестоимости продукции на предприятиях по обработке драгоценных металлов (утв. Приказом Комитета РФ по драгоценным металлам и драгоценным камням от 30 мая 1994 г. № 226).

По «Инструкции по планированию, учету и калькулированию себестоимости продукции на предприятиях по добыче и обработке драгоценных металлов и алмазов» (утв. Роскомдрагметом 28.02.1994) [3] в состав отрасли входят горные предприятия по добыче благородных (золото, серебро, платина) и цветных (олово, вольфрам, сурьма) металлов и алмазов, обогатительные фабрики, заводы по аффинажу, обработке драгоценных металлов и специальных сплавов, по производству вторичных драгоценных металлов. В документе подробно изложены особенности этих производств.

В себестоимость продукции (работ, услуг) включаются затраты по двадцати девяти статьям и охватывают типовые группировки затрат по элементам для каждого производственного направления.

Важной особенностью в формировании себестоимости является исключение из нее затрат на выполнение самим предприятием или оплату им работ (услуг), не связанных с производством продукции (работы по благоустройству городов и поселков, оказание помощи сельскому хозяйству и другие виды работ) и затраты на выполнение работ по строительству, оборудованию и содержанию (включая амортизационные отчисления и затраты на все виды ремонтов) культурно - бытовых и других объектов, находящихся на балансе предприятия, а также работ, выполняемых в порядке оказания помощи и участия в деятельности других предприятий и организаций.
Таким образом, нужно четко разграничить вопрос создания инфраструктуры непосредственно для процесса производства, которая напрямую увеличивает себестоимость продукции и финансирование дополнительных мероприятий, направленных на качественное улучшение и развитие региона. Последняя статья не участвует в формировании себестоимости продукции, но является важной составляющей определяющей цену конкурента.

\section{Цена конкурента и качество сырья}

Конкуренция является двигателем улучшения качества и позволяет потребителю выбирать те товары на рынке, свойства которых соответствуют его требованиям и имеющимся денежным средствам. Конкуренция является действенным методом формирования цены. Однако насколько актуален данный фактор для алмазодобывающей отрасли?

Отличительной чертой мирового алмазного рынка в настоящее время является его высокая монополизация. Крупнейшими добывающими компаниями являются De Beers, АЛРОCA, Rio Tinto, Dominion Diamond и Petra Diamonds (таблица).

На эти компании по добычи приходится более $72 \%$ алмазов по объему и свыше $92 \%$ по стоимости.

Самые крупные месторождения алмазов находятся в Канаде, ЮАР, Ботсване, Намибии и Анголе. Но в самых больших объемах добывают алмазы в России. По информации «Kimberley process» по состоянию на 2017 год именно Российская Федерация лидирует по количеству добытых драгоценных камней. Согласно ежегодному отчету за 2017 год, опубликованному Кимберлийским процессом, в России добыли 42,6 млн. карат алмазов (рисунок 1). В финансовом эквиваленте Россия произвела алмазов на 4,11 млрд. долларов США.

На рисунках 2 и 3 видно наглядно, что Россия по объемам добычи алмазов как в денежном выражении $(29,11 \%)$, так и в каратах $(28,24 \%)$ зани-

Таблица. Компании - крупнейшие производители алмазов

\begin{tabular}{|l|l|}
\hline \multicolumn{1}{|c|}{ Компания } & \multicolumn{1}{c|}{ Страна деятельности } \\
\hline «АЛРОСА» & Россия, Ботсвана \\
\hline De Beers & Ботсвана, ЮАР, Намибия, Канада, Ангола \\
\hline Rio Tinto & Австралия, Канада, Зимбабве, Индия \\
\hline Dominion Diamond & Канада \\
\hline Petra Diamonds & ЮАР, Танзания, Ботсвана \\
\hline
\end{tabular}




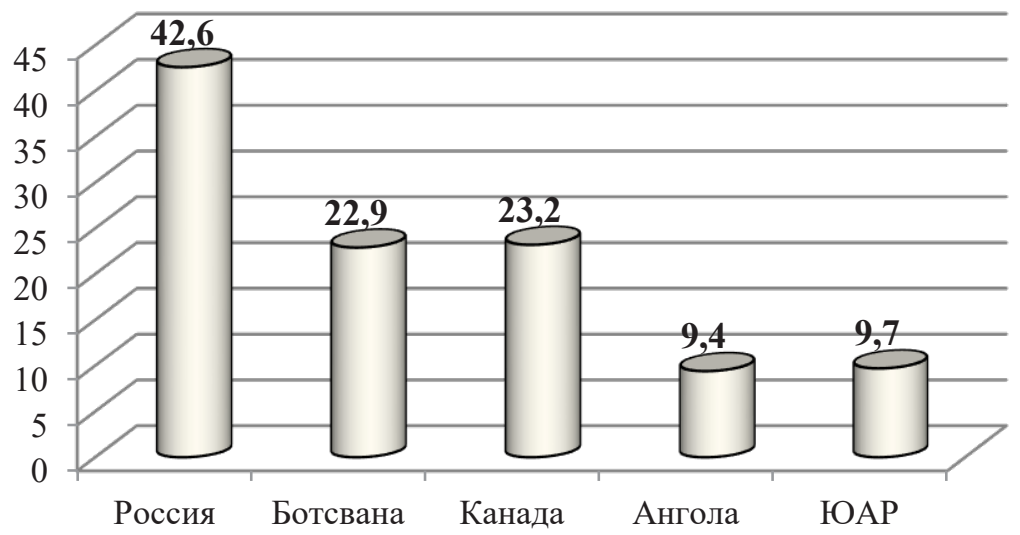

Pис. 1. Показатели добычи алмазов странами мира в 2017 году, млн. карат [5]

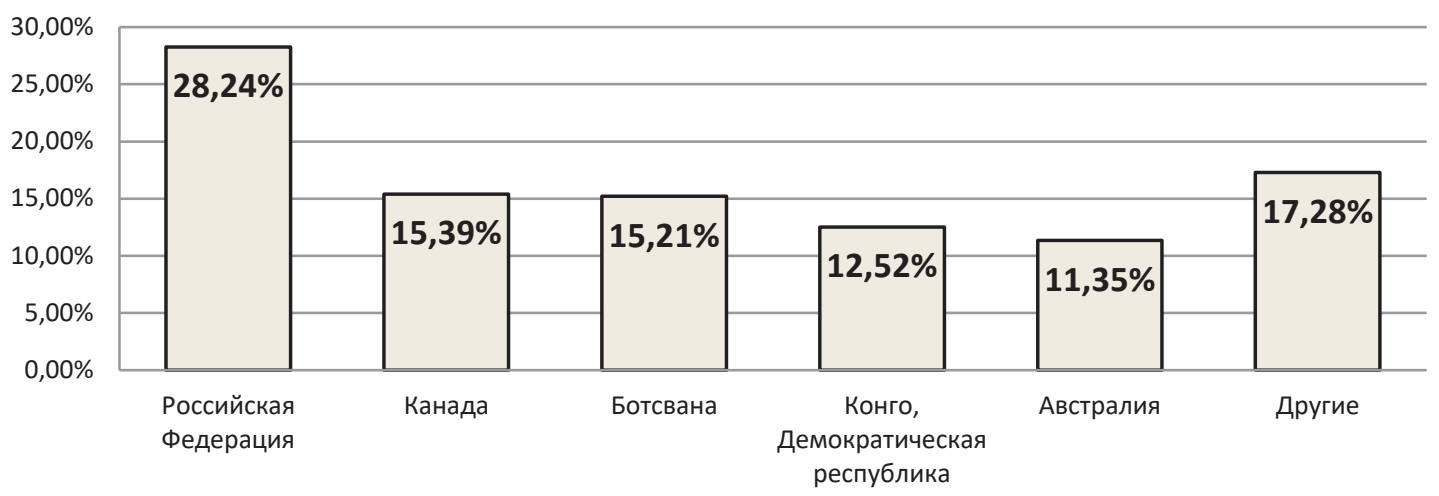

Puc. 2. Доля стран мира по добыче алмазов в 2017 году в каратах,\% [5]

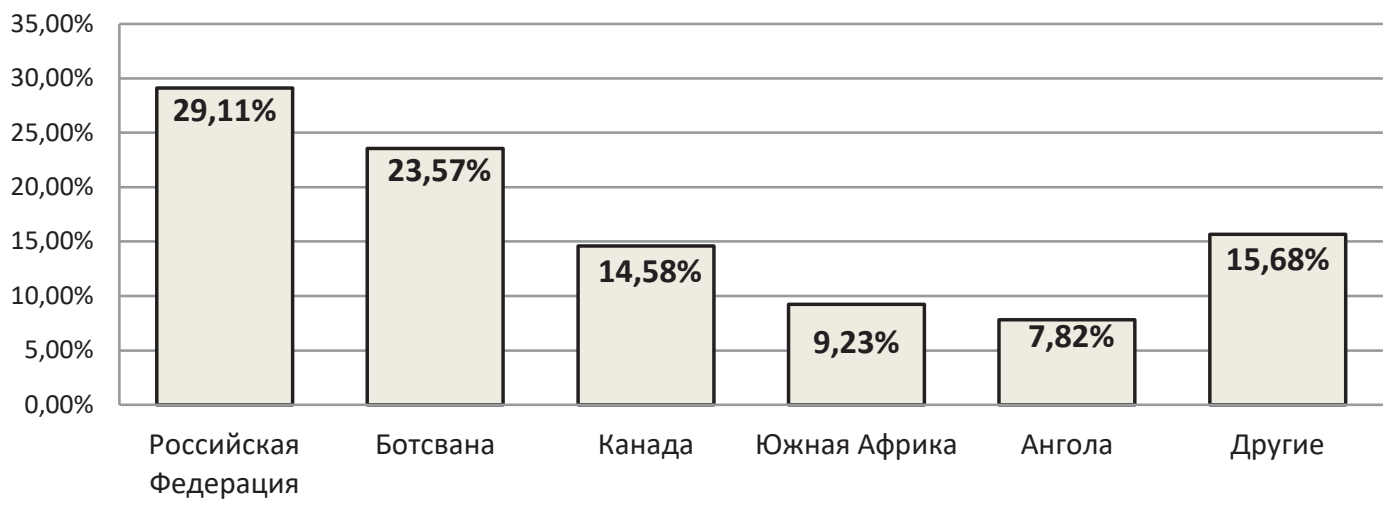

Рuс. 3. Доля стран мира по добыче алмазов в 2017 году финансовом эквиваленте,\% [5] 
мает лидирующее первое место.

Вторую позицию занимает Канада, с показателем объема добычи 23,2 млн. карат (в финансовом эквиваленте - 2,06 млрд. долларов $(14,58 \%))$.

На третьем месте Ботсвана, которая производит 22,9 млн. карат на сумму в 3,33 млрд. долларов (23,57\%).

На сводном графике на рисунке 4 приведены совмещенные показатели добычи и стоимости алмазов по странам в 2017 году. Безусловным лидером по добыче в стоимостном эквиваленте сырья является Россия, за ней следует Ботсвана, ЮАР и Канада.

Сравнительный график свидетельствует о разнородности цены на сырье из разных регионов. Это в свою очередь может означать:

1) принципиальные отличия качественных характеристик продукции;

2) различие себестоимость добычи;

3) другие причины.

Качество и размер алмазов значительно выше в россыпных образованиях. Соответственно, цена на такие алмазы существенно выше. Крупнейшие россыпные месторождения находятся в Демократической Республике Конго, Намибии, ЮАР, Анголе и Бразилии.

Российская минерально-сырьевая база на 95\% представлена коренными месторождениями. Качество руд отечественных месторождений можно назвать высоким - среднее содержание алмазов в кимберлитах коренных месторождений превышает 1 кар/т, при этом пять крупных и гигантских по количеству запасов трубок характеризуются уникальной алмазоносностью - более 3 кар/т (Трубки Интернациональная, Айхал, Ботуобинская и др.) [2]. Качество самих алмазов в целом оценивается как среднее: согласно данным российского Министерства финансов, средняя цена добытых в 2017 г. алмазов составила 95,5 долл./кар. Самые дорогие алмазы добываются в Лесото (1065,9 долл./кар - цена 2016 г.), самые дешевые - в Демократической Республике Конго (ДРК; 10,6 долл./кар - цена 2016 г.).

Ниже приведем для сравнения показатели по качеству сырья для некоторых других мировых продуцентов, кроме России:

1. Ботсвана (главный конкурент России) практически все алмазы добываются на гигантских кимберлитовых трубках Орапа и Джваненг, содержащих в среднем 0,92 кар/т и 1,3 кар/т соответственно.

2. Намибия. Порядка 98\% алмазов относятся к ювелирному, в том числе в кимберлитовых трубках. Небольшие объемы добычи компенсируются высоким качеством, а соответственно и более высокой ценой за карат (518,74 долл/карат).

3. Австралия. Главное месторождение гигантская высокоалмазоносная трубка оливиновых лампроитов Аргайл. Качество алмазов месторождения в целом низкое, в 2016 г. их средняя цена составила лишь 15,5 долл./кар, однако среди камней встречаются редкие алмазы розового цвета.

4. Канада. Кимберлитовые месторождения

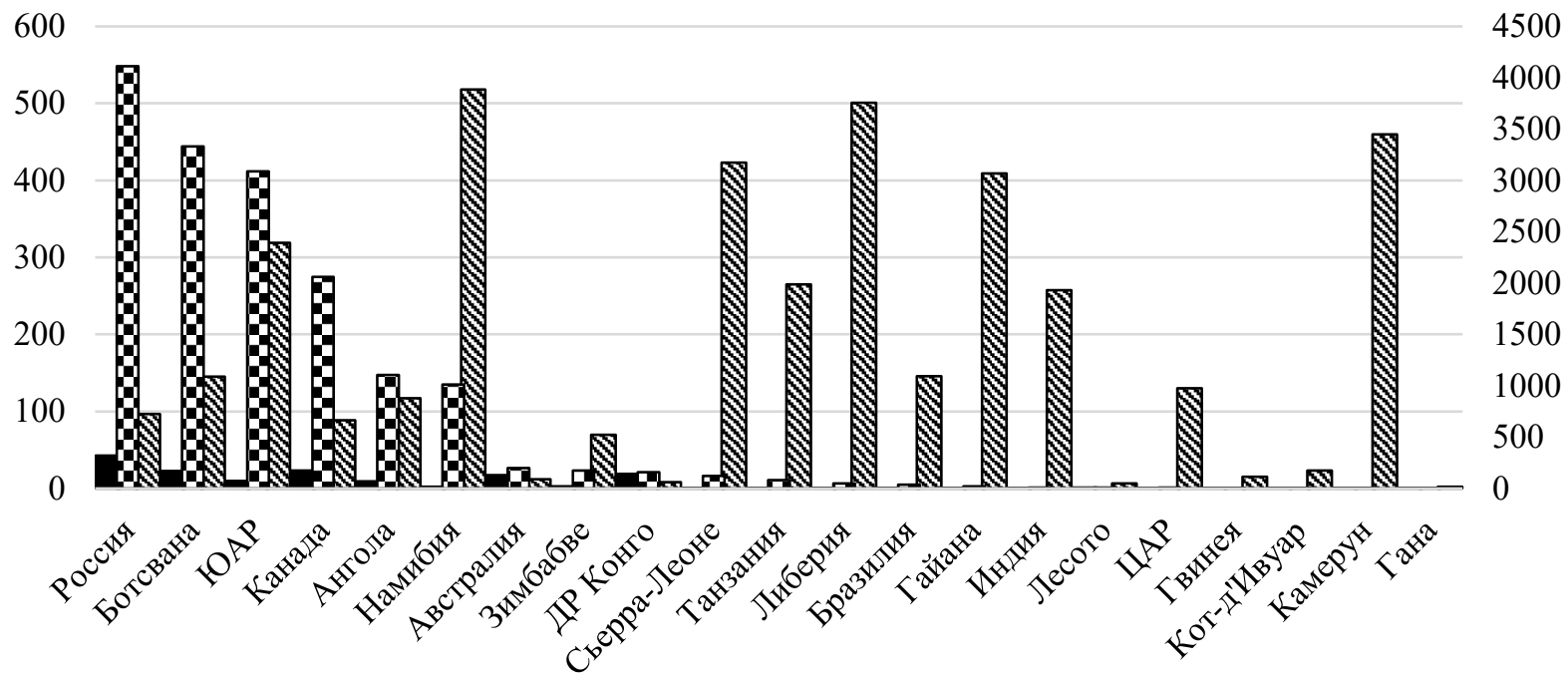

добыча, млн. карат

\$ стоимость алмазов, долл/карат

п добыча, млн. долл.

Puc. 4. Показатели добычи и стоимости алмазов по странам мира в 2017 году [5] 
этой страны значительно уступают по количеству отечественным, однако сопоставимы по качеству. Кроме того, качество руд канадских объектов различно, среднее содержание алмазов варьирует от 0,1 до 3 кар/т.

Очевидно, что цена на ювелирное сырье (Намибия, Бразилия, ЮАР) значительно превосходит цену на техническое сырье (Якутия, Канада). Безусловно, промышленные алмазы также полезны и часто применяются, но в настоящее время все большую популярность приобретают искусственные алмазы. Эти кристаллы по своим свойствам не уступают природным, но при этом себестоимость их значительно ниже. Соответственно, спрос на природные камни будут определять крупные производители бриллиантов, для которых в свою очередь качество сырья (отсутствие дефектов, внешний вид, форма и количество сколов) играет первостепенную роль. Тут как нельзя лучше подходит старая поговорка «на что спрос, на то и цена» и таким странам как
Россия и Канада удается удерживаться в лидерах отрасли исключительно за счет объемов добычи (см. рис 1,4).

Таким образом, в результате проведенного исследования можно резюмировать, что формирование цены на алмазы, как продукцию добычного предприятия, не всегда описывается известной формулой цены = издержки + прибыль. Наряду с основными составляющими себестоимости, которые подвергаются регламентации и учету, огромную роль играет цена и качество продукции конкурента. В настоящее время ювелирное сырье более востребовано. Технические алмазы природного происхождения все больше заменяются искусственными, себестоимость которых значительно ниже. Качество сырья определяет не только ценовой диапазон продаж, но и объемы добычи и реализации. Как показывает анализ добычи - максимальные объемы показывают страны, в которых алмазное сырье по своему качеству рядовое.

\section{Библиографический список}

1. Где и как добывают алмазы в России и мире? [Электронный ресурс]// Режим доступа: URL //https://vkamen. $\mathrm{ru}$ /interesno/dobycha-almazov.

2. Государственный доклад «О состоянии и использовании минерально-сырьевых ресурсов Российской Федерации в 2016 и 2017 годах».URL: http://www.mnr.gov.ru/docs/gosudarstvennye_doklady/o_sostoyanii_i_ ispolzovanii_mineralno_syrevykh_resursov_rossiyskoy_federatsii/.

3. Инструкция по планированию, учету и калькулированию себестоимости продукции на предприятиях по добыче и обработке драгоценных металлов и алмазов (утв. Роскомдрагметом 28.02.94).

4. Ларин В.Н. Наша Земля (происхождение, состав, строение и развитие изначально гидридной Земли). Москва. 2005. С. 48.

5. The Kimberley Process Rough Diamond Statistics. URL: https://kimberleyprocessstatistics.org/links. 